\title{
Decline in the incidence of invasive pneumococcal disease at a medical center in Taiwan, 2000-2012
}

\author{
Chih-Cheng Lai ${ }^{1}$, Sheng-Hsiang Lin ${ }^{2,3}$, Chun-Hsing Liao ${ }^{4}$, Wang-Huei Sheng ${ }^{5}$ and Po-Ren Hsueh ${ }^{5,6^{*}}$
}

\begin{abstract}
Background: It is essential to investigate the serotype distribution of pneumococcal diseases in each region and its associated clinical features. This study investigated the annual incidence of invasive pneumococcal disease (IPD) and the distribution of serotypes of isolates causing IPD at a medical center in northern Taiwan during the period 2000 to 2012.

Methods: Serotypes of all available Streptococcus pneumoniae isolates causing IPD were determined using the latex agglutination test.

Results: During the study period, the annual incidence (per 10,000 admissions) of IPD decreased significantly from 9.8 in 2000 to 2.1 in $2012(P<0.001)$. The annual incidence of all-cause bacteremia, primary pneumococcal bacteremia, bacteremic pneumonia, peritonitis, and meningitis also decreased significantly during the study period $(P<0.05)$. In contrast to the decrease in annual incidence of pneumococcal serotypes $14,23 \mathrm{~F}$ and $6 \mathrm{~B}$, the incidence and the proportion of serotype $19 \mathrm{~A}$ significantly increased with time $(P<0.001)$. The coverage rate of 7 -valent protein conjugated vaccine (PCV-7) and PCV-10 decreased significantly; however, the coverage rate of PCV-13 and pneumococcal polysaccharide vaccine (PPV-23) remained stable over time. Serotype 14 and 19A isolates were commonly isolated from blood and pleural effusion, respectively. Serotypes 14 and $23 \mathrm{~F}$ were the two most common serotypes found in adult patients, and serotypes 14 and 19A were the two most common serotypes isolated from children.
\end{abstract}

Conclusions: Although the incidence of IPD has decreased, serotype 19A is an emerging problem in Taiwan. The distribution of serotypes of pneumococci varied with clinical symptoms and age. As the changing distribution of pneumococcal serotype with time, the coverage rate of pneumococcal vaccines would be different.

Keywords: Invasive pneumococcal disease, Incidence, Streptococcus pneumoniae, Serotypes

\section{Background}

Streptococcus pneumoniae is a well known etiology of acute otitis media, pneumonia, bloodstream infections, peritonitis, and meningitis [1-5]. Although there are 92 different capsular serotypes, which have been categorized into 46 serogroups based on immunological characteristics [6], less than 30 types account for more than $90 \%$ of invasive pneumococcal disease (IPD) [7]. Different serotypes have distinct features, which may be more frequently associated with specific disease patterns. For

\footnotetext{
* Correspondence: hsporen@ntu.edu.tw

${ }^{5}$ Department of Internal Medicine, National Taiwan University Hospital,

National Taiwan University College of Medicine, Taipei, Taiwan

${ }^{6}$ Department of Laboratory Medicine, National Taiwan University Hospital,

National Taiwan University College of Medicine, Taipei, Taiwan

Full list of author information is available at the end of the article
}

example, serotypes $3,6 \mathrm{~B}, 14,23 \mathrm{~F}$ can cause more severe meningeal inflammation than serotypes $1,5,9$, and $7 \mathrm{~F}$ in experimental meningitis $[8,9]$. In a murine model of pneumococcal sepsis, certain serotypes were more fatal than other serotypes [10]. Moreover, the distribution of serotypes varies according to patient's age, disease pattern, and geographical region [1].

Although the mortality rate associated with IPD is as high as 35\% [11-14], pneumococcal vaccination was developed to prevent several serotypes. Furthermore, serotype distribution can be affected by the implementation of vaccination [1]. Most important of all, novel vaccine development should be based on knowledge of the incidence rate of each pneumococcal serotype. When facing this life-threatening disease, it is essential to investigate

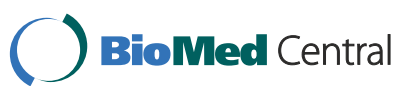

(c) 2014 Lai et al.; licensee BioMed Central Ltd. This is an Open Access article distributed under the terms of the Creative Commons Attribution License (http://creativecommons.org/licenses/by/2.0), which permits unrestricted use, distribution, and reproduction in any medium, provided the original work is properly credited. The Creative Commons Public Domain Dedication waiver (http://creativecommons.org/publicdomain/zero/1.0/) applies to the data made available in this article, unless otherwise stated. 
the serotype distribution in each region and its associated clinical features. Therefore, we investigated the serotype distribution of various types of IPD and the trend with time from 2000 to 2012 at a medical center in Taiwan.

\section{Methods}

Hospital setting and patient selection

This study was conducted at the National Taiwan University Hospital (NTUH). NTUH has a 2500-bed and around 8000 daily clinical visits, and is a both primary care and tertiary care center in northern Taiwan. Patients whose blood, cerebrospinal fluid (CSF), pleural effusion, ascites, or aspirated ear and sinus fluid cultures yielded S. pneumoniae during 2000-2012 were identified from the computerized database of the bacteriology laboratory.

\section{Bacterial isolates and serotype study}

Pneumococcal isolates were identified by recognition of typical colony morphology on trypticase soy agar supplemented with 5\% sheep blood (BBL Microbiology Systems, Cockeysville, MD), Gram staining characteristics, susceptibility to ethylhydrocupreine hydrochloride (optochin) (Difco Laboratories, Detroit, MI) and bile solubility. Serotypes were determined for available isolates by latex agglutination (Pneumotest-Latex; Statens Serum Institut, Copenhagen, Denmark) according to the manufacturer's instructions and were confirmed by the Quellung reaction $[15,16]$.

\section{Definition}

IPD was diagnosed in patients from whom S. pneumoniae was isolated from a normally sterile site, such as blood, cerebrospinal fluid, pleural fluid, or ascites. Pneumococcal meningitis was diagnosed in patients from whom pneumococci were isolated from CSF. The diagnoses of pneumococcal empyema, peritonitis, sinusitis, and otitis media were established based on culture results positive for $S$. pneumoniae obtained from pleural fluid, ascites, aspirated sinus, and ear fluid, respectively. Primary pneumococcal bacteremia was defined as isolation of pneumococcus from blood without a focus. The annual incidence of each type of IPD was defined as the number of patients with pneumococcal infections per 10,000 admissions per year.

\section{Statistical analysis}

The chi-square test was used for dichotomous variables. We used the chi-square test for trend to assess temporal trends in incidence. A P value of $<0.05$ was considered to be statistically significant.

\section{Results}

\section{Secular trend of incidence of IPD}

During the study period, IPD was diagnosed in 458 patients and of those patients, 423 had bacteremia. Empyema was found in $52(11.4 \%)$ patients, peritonitis was found in $22(4.8 \%)$ patients, and meningitis was found in $6(1.3 \%)$ patients. Additionally, 25 cases of culture-confirmed sinusitis and 25 cases of culture-confirmed otitis media were identified during the study period. The yearly admission number gradually increased with time $(P<0.05)$, ranging from 55,920 in 2000 to 85,253 in 2012 (Table 1). The annual incidence of each type of IPD per 10,000 admissions is shown in Table 1 and Figure 1A and B. In children, the annual incidence of IPD significantly decreased from 41.2 per 10,000 admissions in 2000 to 15.2 per 10,000 admissions in $2012(P<0.001)$. In adult, the annual incidence of IPD significantly decreased from 5.0 per 10,000 admissions in 2000 to 1.5 per 10,000 admissions in $2012(P<0.001)$. The overall annual incidence of IPD significantly decreased from 9.8 per 10,000 admissions in 2000 to 2.1 per 10,000 admissions in $2012(P<0.001)$. Additionally, the annual incidence of all-cause bacteremia, primary bacteremia, bacteremic pneumonia, peritonitis, and meningitis due to S. pneumoniae significantly decreased with time $(P<0.05)$. The annual incidence of empyema, pneumonia without bacteremia, sinusitis and otitis media remained stable between 2000 and 2012. Figure 1C shows the annual incidence of major serotypes of $S$. pneumoniae causing IPD. The annual incidence of serotypes $14,23 \mathrm{~F}$ and $6 \mathrm{~B}$ significantly decreased with time; however, the incidence of serotypes $19 \mathrm{~A}$ significantly increased $(\mathrm{P}<0.001)$. There was no significant change in annual incidence of serotypes 3 and 19F $(P=0.172$ and $P=0.08)$.

\section{Serotype distribution in adults and children}

During the study period, a total of 443 isolates from 443 patients with IPD were available for serotype studies. The annual distribution of main capsular serotypes of S. pneumoniae isolates causing IPD is shown in Figure 2. For all patients, the proportion of serotype 19A increased from $<20 \%$ between 2000 and 2007 to $48.0 \%-50.0 \%$ between 2011 and $2012(P<0.001)$. Table 2 shows the serotype distribution in adults, children, and all patients. Among all patients, serotype 14 was the most common serotype $(n=106,23.9 \%)$, followed by serotype $23 F(n=57$, $12.9 \%)$, and serotype $6 B(n=53,12.0 \%)$. Serotype 14 was also the most common serotype found in adult patients, followed by serotype $23 \mathrm{~F}$, and $6 \mathrm{~B}$. In contrast, the second most common serotype in children was serotype 19A, followed by serotype $19 \mathrm{~F}$.

There was a significant increase in incidence of serotype 19A $(P<0.001)$, but a significant decline in incidence of serotypes $14,23 \mathrm{~F}$, and $6 \mathrm{~B}$ over time. For adult patients, the incidence of serotype 19A significantly increased $(P<0.001)$. For children, the incidence of serotype 19A rose from $<5 \%$ between 2000 and 2008 to $71.4 \%-$ 75.0\% between 2011 and $2012(P<0.001)$. The incidence of serotype 3 significantly increased $(P<0.001)$, but that of 
Table 1 Annual incidence of patients with each type of invasive pneumococcal disease (IPD), sinusitis, and otitis media at National Taiwan University Hospital from 2000 to 2012

\begin{tabular}{|c|c|c|c|c|c|c|c|c|c|c|c|c|c|c|}
\hline \multirow[t]{2}{*}{ Disease } & \multicolumn{13}{|c|}{ Incidence expressed as no. of patients per 10,000 admission (no. of patients) } & \multirow[t]{2}{*}{$P$ value } \\
\hline & $\begin{array}{c}2000 \\
(n=55920)\end{array}$ & $\begin{array}{c}2001 \\
(\mathrm{n}=66743)\end{array}$ & $\begin{array}{c}2002 \\
(n=62177)\end{array}$ & $\begin{array}{c}2003 \\
(n=54574)\end{array}$ & $\begin{array}{c}2004 \\
(n=64186)\end{array}$ & $\begin{array}{c}2005 \\
(n=67853)\end{array}$ & $\begin{array}{c}2006 \\
(n=70814)\end{array}$ & $\begin{array}{c}2007 \\
(n=73534)\end{array}$ & $\begin{array}{c}2008 \\
(n=74505)\end{array}$ & $\begin{array}{c}2009 \\
(n=78756)\end{array}$ & $\begin{array}{c}2010 \\
(n=79710)\end{array}$ & $\begin{array}{c}2011 \\
(n=81594)\end{array}$ & $\begin{array}{c}2012 \\
(\mathrm{n}=85253)\end{array}$ & \\
\hline IPD & 9.8 & 7.6 & 8.0 & 5.9 & 8.4 & 4.6 & 4.0 & 3.0 & 4.6 & 3.6 & 3.8 & 3.1 & 2.1 & $<0.001$ \\
\hline All bacteremia & 9.3 & 7.3 & 7.1 & 5.1 & 7.9 & 4.1 & 3.8 & 2.9 & 4.2 & 3.4 & 3.4 & 2.7 & 1.9 & $<0.001$ \\
\hline $\begin{array}{l}\text { Primary } \\
\text { bacteremia }\end{array}$ & 6.8 & 4.8 & 4.2 & 3.7 & 5.9 & 3.8 & 2.8 & 2.2 & 3.4 & 3.0 & 2.5 & 2.0 & 0.8 & $<0.001$ \\
\hline $\begin{array}{l}\text { Bacteremic } \\
\text { pneumonia }\end{array}$ & 0.9 & 1.9 & 1.6 & 0.9 & 1.1 & 0.3 & 0.7 & 0.5 & 0.4 & 0.4 & 0.6 & 0.4 & 0.6 & $<0.001$ \\
\hline Empyema & 1.3 & 0.4 & 1.3 & 1.1 & 0.3 & 0.3 & 0.3 & 0.3 & 0.7 & 0.1 & 0.4 & 0.6 & 0.7 & 0.070 \\
\hline Peritonitis & 0.4 & 0.1 & 0.2 & 0.0 & 0.2 & 0.0 & 0.0 & 0.0 & 0.1 & 0.0 & 0.0 & 0.0 & 0.0 & $<0.009$ \\
\hline Meningitis & 0.5 & 0.3 & 0.8 & 0.2 & 0.9 & 0.1 & 0.1 & 0.0 & 0.0 & 0.0 & 0.3 & 0.1 & 0.0 & $<0.001$ \\
\hline \multicolumn{15}{|l|}{ Non-IPD } \\
\hline $\begin{array}{l}\text { Pneumonia } \\
\text { without } \\
\text { bacteremia }\end{array}$ & 16.8 & 18.4 & 24.1 & 19.1 & 23.2 & 23.4 & 27.1 & 23.0 & 25.6 & 22.1 & 23.5 & 15.0 & 12.7 & $<0.054$ \\
\hline Sinusitis & 0.2 & 0.3 & 0.3 & 0.2 & 0.6 & 0.3 & 0.3 & 0.4 & 0.4 & 0.0 & 0.3 & 0.1 & 0.2 & 0.439 \\
\hline Otitis media & 0.4 & 0.3 & 0.2 & 0.2 & 0.5 & 0.3 & 0.3 & 0.4 & 0.3 & 0.3 & 0.0 & 0.2 & 0.4 & 0.69 \\
\hline
\end{tabular}




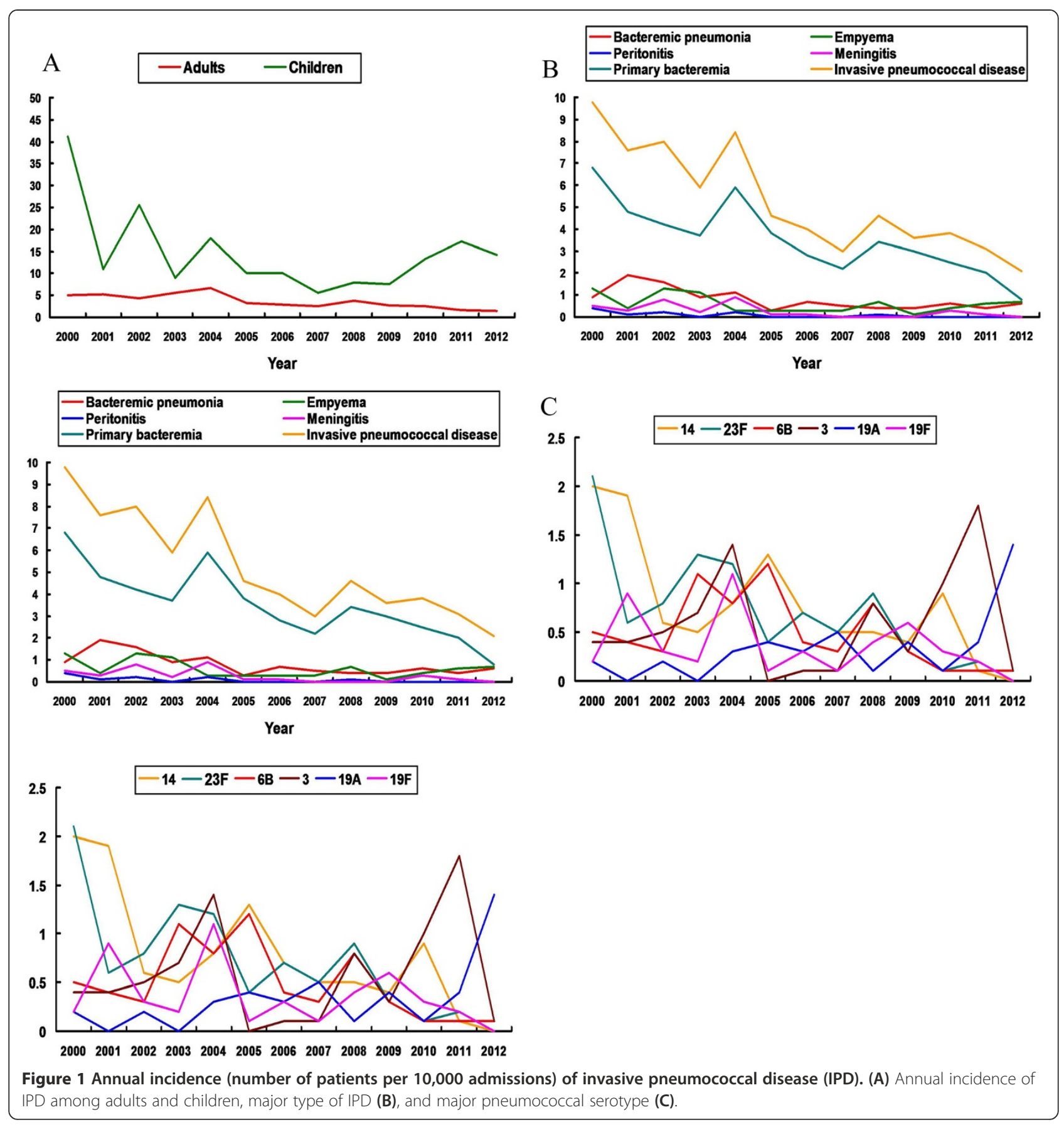

serotypes $23 \mathrm{~F}$ and $19 \mathrm{~F}$ significantly decreased $(P=0.027$, and $P=0.049$ ).

\section{Serotype distribution in different types of IPD}

Blood was the most common source of isolates $(n=370$, $83.5 \%)$, followed by pleural effusion ( $\mathrm{n}=46,10.4 \%)$, CSF (21, 4.7\%), and ascites $(n=6,1.4 \%)$. Serotype $14(n=88$, $23.8 \%$ ) was the most common serotype isolated from blood specimens and serotype 19A $(\mathrm{n}=14,30.4 \%)$ was the most common serotype isolated from pleural effusion. In addition, serotype $6 \mathrm{~B}$ was the most common serotype isolated from CSF and serotype 19F was the most common serotype isolated from ascites specimens.

\section{Vaccine coverage}

The coverage rates of conjugated vaccines including PCV-7 (PrevnarR; Pfizer), PCV-10 (Synflorix; GSK), PCV-13 (Prevnar 13; Pfizer) and PPV-23 (Pneumovax 23; Merck 


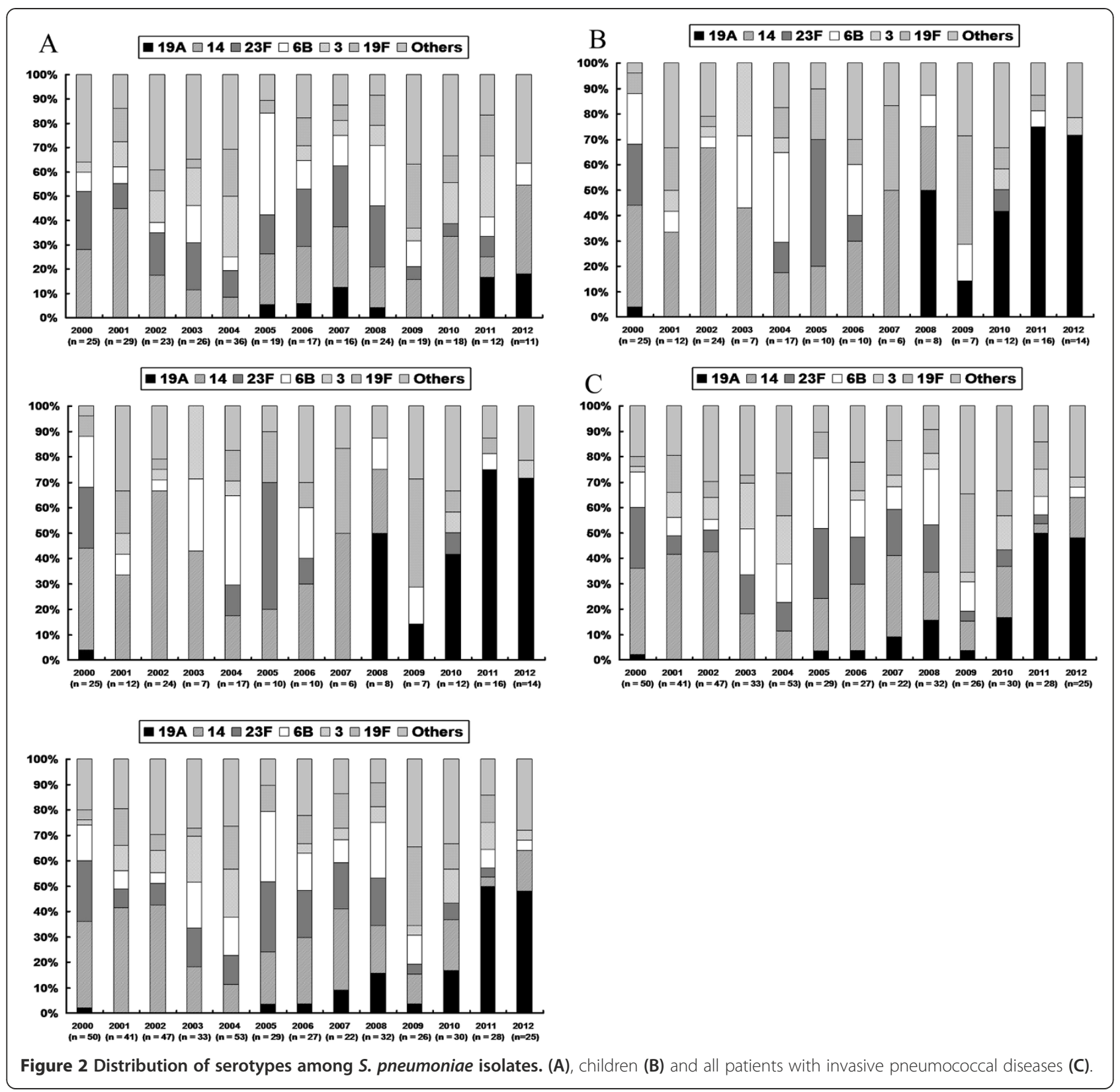

Sharp \& Dohme Corp.) are shown in Figure 3. The overall coverage rates during the period 2000-2012 were $65.2 \%$ for PCV-7, 65.9\% for PCV-10, $85.8 \%$ for PCV-13, and 91.2\% for PPV-23. The coverage rates of PCV-7 and PCV10 significantly decreased with time, but the PCV-13 and PPV-23 coverage rates remained stable. Moreover, PCV-7 and PCV-10 had only a $25 \%$ coverage rate in 2012 . In contrast, the coverage rates of PCV-13 and PCV-23 were each $80.0 \%$ in 2012. The reason coverage of PCV-13 was better than that of PPV-23 in 2010 and 2011 is that there were four serotype 6A isolates found in 2010 and two serotype $6 \mathrm{~A}$ isolates found in 2011 that were covered by PCV-13 but not by PPV-23.

\section{Discussion}

This study investigated the epidemiology of IPD and the trends and changes in distribution of pneumococcal serotypes in a large Taiwanese hospital over a 13 year period. We found that the incidence of most pneumococcal diseases, including all-cause bacteremia, primary bacteremia, bacteremic pneumonia, peritonitis, and meningitis, significantly decreased with time during study period. In addition, the annual incidence of several pneumococcal serotypes, including serotypes $14,23 \mathrm{~F}$, and $6 \mathrm{~B}$ significantly decreased with time. In Taiwan, PPV-23 was introduced in 2001 and the cumulative vaccination rate among people aged $\geq 75$ years reached $12 \%$ in 2007 and $41 \%$ in 2008 . 
Table 2 Distribution of major serotypes of 443 isolates of S. pneumoniae causing invasive pneumococcal disease in adults and children treated National Taiwan University Hospital from 2000 to 2012

\begin{tabular}{|c|c|c|c|c|c|c|}
\hline \multirow[t]{2}{*}{ Serotype } & \multicolumn{2}{|c|}{ Adults $(n=275)$} & \multicolumn{2}{|c|}{ Children $(n=168)$} & \multicolumn{2}{|c|}{ Total $(n=443)$} \\
\hline & No. & $\%$ & No. & $\%$ & No. & $\%$ \\
\hline 14 & 60 & 21.9 & 46 & 27.4 & 106 & 23.9 \\
\hline $23 \mathrm{~F}$ & 42 & 15.3 & 15 & 8.9 & 57 & 12.9 \\
\hline $6 B$ & 33 & 12.0 & 20 & 11.9 & 53 & 12.0 \\
\hline 3 & 31 & 11.3 & 7 & 4.2 & 38 & 8.6 \\
\hline $19 F$ & 30 & 10.9 & 17 & 10.1 & 47 & 10.6 \\
\hline 4 & 9 & 3.3 & 0 & 0.0 & 9 & 2.0 \\
\hline $19 A$ & 9 & 3.3 & 33 & 19.6 & 42 & 9.5 \\
\hline $9 \mathrm{~V}$ & 7 & 2.5 & 5 & 3.0 & 12 & 2.7 \\
\hline $23 \mathrm{~A}$ & 7 & 2.5 & 1 & 0.6 & 8 & 1.8 \\
\hline $15 B$ & 5 & 1.8 & 9 & 5.4 & 14 & 3.2 \\
\hline 20 & 5 & 1.8 & 2 & 1.2 & 7 & 1.6 \\
\hline Others & 37 & 13.5 & 13 & 7.7 & 50 & 11.3 \\
\hline Total & 275 & 100 & 168 & 100 & 443 & 100 \\
\hline
\end{tabular}

PCV-7 was introduced in October 2005 and the cumulative vaccination rate among children aged $<5$ years was $0.7 \%$ in $2005,8.6 \%$ in $2006,15.9 \%$ in 2007 , and $25.2 \%$ in 2008 [16]. In contrast, PCV-10 and PCV-13 were introduced in Taiwan in 2010, and 2011, respectively. Therefore, our encouraging finding can be attributed to the introduction of PPV-23 and PCV-7. However, we found an increase in the incidence and proportion of serotype 19A among all serotypes causing IPD, especially in children. Although PPV-23 can cover serotype 19A, the use of this vaccine is limited in elderly patients with age above 65 years. Therefore, the emergence of serotype 19A, especially in children in Taiwan may be due to inadequate coverage of vaccination. Moreover, our findings suggest that the secular trend in pneumococcal serotype distribution needs to be closely monitored and that the use of vaccination needs to be adjusted according to the change in serotype distribution.

We found that the coverage rate of PCV-7 and PCV10 declined from more than $80 \%$ in 2000 to $20 \%$ in 2012. In contrast, that of PPV-23 and PCV-13 remained stable, ranging from $75 \%$ to $97 \%$ during the study period. The difference can be attributed to the fact that PPV-23 and PCV-13 cover serotypes 19A and 3. Moreover, PCV-13

\section{PPV-23 - PCV-7 - PCV-10 - PCV-13}

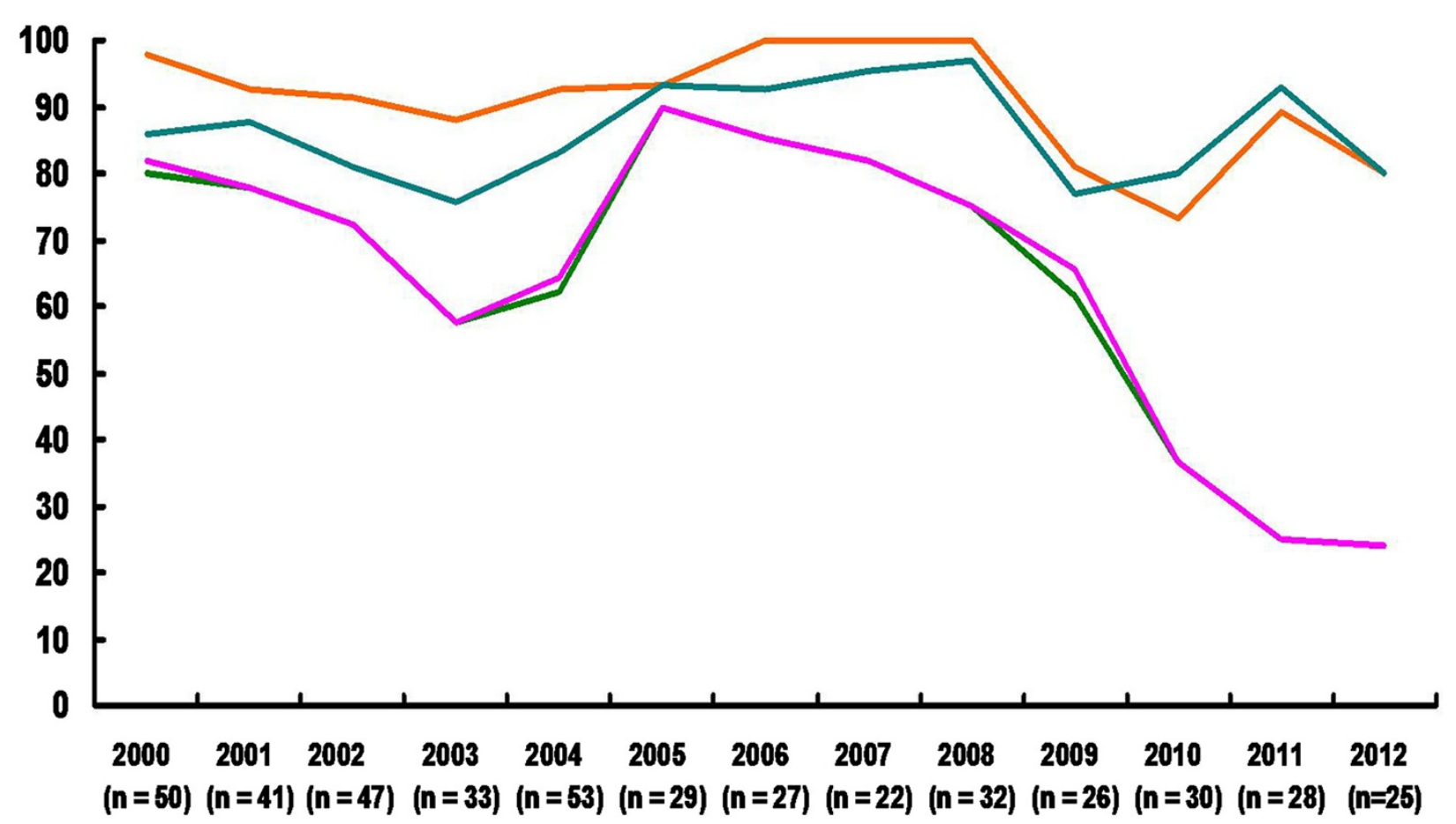

Figure 3 Coverage rates of different pneumococcal vaccines among S. pneumoniae isolates recovered from patients with invasive pneumococcal diseases at National Taiwan University Hospital from 2000 to 2012. 
can cover serotype $6 \mathrm{~A}$ but PPV-23 cannot. All of the 8 cases of serotype $6 \mathrm{~A}$ isolates were found within the last four years (2009 to 2012). Therefore, the clinical impact of PCV-13 for serotype 6A deserves further attention. Based on our findings, PPV-23 and PCV-13 may be a better choice of vaccine to prevent IPD in Taiwan. However, PCV-13 is a newly introduced vaccine in Taiwan; therefore, further surveillance studies are warranted.

We also found that the serotype distribution differed among different diseases. For example, serotype 14 was the most common serotype causing pneumococcal bacteremia in both adults and children [17] and was also the predominant serotype causing empyema in children. In addition to serotype 14 , serotypes $3,6 \mathrm{~B}, 19 \mathrm{~F}$, and $23 \mathrm{~F}$ were the most common serotypes causing bacteremia in adults. In children, serotypes 6B, 19A, 19F, and 23F were common serotypes causing bacteremia. In addition, most cases of meningitis in children and adults were caused by serogroups $6(n=7)$, and $23(n=5)$. In contrast, only one patient had serotype 14 meningitis. This finding is consistent with a previously reported finding that serogroups 6,10 , and 23 are more frequently isolated from CSF than serotypes 1, 4, and 14 [17]. Serotype $19 \mathrm{~F}$ was isolated from 4 of the 6 patients with pneumococcal peritonitis. We also found that some uncommon serotypes were associated with their own distinct syndromes. For example, all patients $(n=9)$ with serotype 4 and all patients $(n=3)$ with serotype $22 \mathrm{~F}$ were adults with bacteremia. In summary, our findings as well as those reported previously [17-20] suggest that some serotypes have a propensity to invade one clinical site rather than another and may therefore be disproportionately responsible for certain disease manifestations. In the present study, serotypes 19A, 14, and 23F were the most common strains causing empyema. This finding differs from that reported in a recent UK study [21], which showed that serotypes $1,3,7 \mathrm{~F}$, and 19A were most frequently implicated in pneumococcal parapneumonic effusion. This difference may be due to geographical differences.

We also found that the distribution of serotypes differed among different age groups. Although serotype 14 was the predominant serotype in adults and children, the second most common serotype differed between the two age groups. In addition, although serotype 19A was the second most common serotype in children (14.9\%), only $2.7 \%$ of cases of IPD in adult patients were caused by serotype 19A pneumonococcus. This finding is similar to that recently reported in a study from China, which demonstrated that serotype 19A strains were more frequently isolated from children with IPD [22]. However, our findings differed from those recently reported in a study from Argentina, which showed that serotypes $14,1,19 \mathrm{~A}, 5,12 \mathrm{~F}, 6 \mathrm{~B}$, and $18 \mathrm{C}$ were the most prevalent serotypes in patients with IPD [23]. In our study, serotype 23A was the second most common serotype in adult patients (15.9\%), but only accounted for $9.7 \%$ of cases of IPD in children. In addition, serotype 4 only caused pneumococcal infection in nine adult patients. The above-mentioned findings suggest that the distribution of pneumococcal serotypes varies according to different age groups.

This study had one major limitation. We might not have captured all cases of IPD because changes might occur in practices that could have affected rates of culture collection or culture positivity. However, this 13-year longitudinal investigation in a medical center in Taiwan still provided the useful information concerning epidemiology of IPD, and possible impact of pneumococcal vaccination. Most important of all, it might help to guide our government in the implementation of an effective pneumococcal vaccination program.

\section{Conclusions}

Despite we might have missed some cases of IPD in this study, we found that IPD caused by serotype 19A $S$. pneumoniae is an emerging problem in Taiwan, although the incidence of IPD has decreased. The distribution of serotypes of pneumococcal isolates causing IPD varies according to clinical syndromes, and age. As the changing distribution of pneumococcal serotype with time, the coverage rate of each pneumococcal vaccine would be different.

\section{Competing interests}

All authors declare that they have no competing interests.

\section{Authors' contributions}

CCL draft the manuscript; SHL analyze the data; CHL and WHS collect the data; PRH complete the manuscript. All authors read and approval the final manuscript before submission.

\section{Author details}

${ }^{1}$ Department of Intensive Care Medicine, Chi Mei Medical Center, Liouying, Tainan, Taiwan. ${ }^{2}$ Department of Respiratory Therapy, Fu Jen Catholic University, New Taipei City, Taiwan. ${ }^{3}$ Department of Internal Medicine, New Taipei City Hospital, New Taipei City, Taiwan. ${ }^{4}$ Department of Internal Medicine, Far Eastern Memorial Hospital, New Taipei City, Taipei County, Taiwan. ${ }^{5}$ Department of Internal Medicine, National Taiwan University Hospital, National Taiwan University College of Medicine, Taipei, Taiwan. ${ }^{6}$ Department of Laboratory Medicine, National Taiwan University Hospital, National Taiwan University College of Medicine, Taipei, Taiwan.

Received: 14 October 2013 Accepted: 4 February 2014 Published: 11 February 2014

\section{References}

1. Hausdoff WP, Feikin DR, Klugman KP: Epidemiological differences among pneumococcal serotype. Lancet Infect Dis 2005, 5:83-93.

2. Garcia-Vidal C, Ardanuy C, Gudiol C, Cuervo G, Calatayud L, Bodro M, Duarte R, Fernández-Sevilla A, Antonio M, Liñares J, Carratalà J: Clinical and microbiological epidemiology of Streptococcus pneumoniae bacteremia in cancer patients. J Infect 2012, 65:521-527.

3. Chen LF, Chen HP, Huang YS, Huang KY, Chou P, Lee CC: Pneumococcal pneumonia and the risk of stroke: a population-based follow-up study. PLoS One 2012, 7:e51452. 
4. Pichon B, Ladhani SN, Slack MP, Segonds-Pichon A, Andrews NJ, Waight PA, Miller E, George R: Changes in the molecular epidemiology of Streptococcus pneumoniae causing meningitis following the introduction of pneumococcal conjugate vaccination in England and Wales. J Clin Microbiol 2013, 51:820-827.

5. Rueda AM, Serpa JA, Matloobi M, Mushtaq M, Musher DM: The spectrum of invasive pneumococcal disease at an adult tertiary care hospital in the early 21st century. Medicine (Baltimore) 2010, 89:331-336.

6. Henrichsen J: Six newly recongnized types of Streptococcus pneumoniae. J Clin Microbiol 1995, 33:2759-2762.

7. Konradsen HB, Kaltoft MS: Invasive pneumococcal infections in Denmark from 1995 tto 1999. Clin Diagn Lab Immunol 2002, 9:358-365.

8. Täuber MG, Burroughs M, Niemöller UM, Kuster $H$, Borschberg U, Tuomanen E: Difference pathophysiology in experiemental meningitis cause- by three strains of Streptococcus pneumoniae. $\mathrm{J}$ Infect Dis 1991, 163:806-811.

9. Engelhard D, Pomeranz S, Gallily R, Strauss N, Tuomanen E: Serotpye-related differences in inflammatory response to Streptococcus pneumoniae in experimental meningitis. J Infect Dis 1997, 175:979-982.

10. Briles DE, Crain MJ, Gray BM, Forman C, Yother J: Strong association between capsular type and virulence for mice among human isolates of Streptococcus pneumoniae. Infect Immun 1992, 60:111-116.

11. Kalin M, Ortqvist A, Almela M, Aufwerber E, Dwyer R, Henriques B, Jorup C, Julander I, Marrie TJ, Mufson MA, Riquelme R, Thalme A, Torres A, Woodhead MA: Prospective study of prognostic factors in communityacquired bacteremic pneumococcal diseases in 5 countires. $J$ Infect Dis 2000, 182:840-847.

12. Moroney JF, Fiore AE, Harrison LH, Patterson JE, Farley MM, Jorgensen JH, Phelan M, Facklam RR, Cetron MS, Breiman RF, Kolczak M, Schuchat A: Clinical outcomes of bacteremic pneumococcal pneumonia in the era of antibiotic resistance. Clin Infect Dis 2001, 33:797-805.

13. Robinson KA, Baughman W, Rothrock G, Barrett NL, Pass M, Lexau C, Damaske B, Stefonek K, Barnes B, Patterson J, Zell ER, Schuchat A, Whitney CG, Active Bacterial Core Surveillance (ABCs)/Emerging Infections Program Network: Epidemiology of invasive Streptococcus pneumoniae infections in the United States, 1995-1998: opportunities for prevention in the conjugate vaccine era. JAMA 2001, 285:1729-1735.

14. Stanek RJ, Mufson MA: A 20-year epidemiological study of pneumococcal meningitis. Clin Infect Dis 1999, 28:1265-1272.

15. Tsai HY, Chen YH, Liao CH, Lu PL, Huang CH, Lu CT, Chuang YC, Tsao SM, Chen YS, Liu YC, Chen WY, Jang TN, Lin HC, Chen CM, Shi ZY, Pan SC, Yang JL, Kung HC, Liu CE, Cheng YJ, Liu JW, Sun W, Wang LS, Ko WC, Yu KW, Chiang PC, Lee MH, Lee CM, Hsu GJ, Hsueh PR: Trends in the antimicrobial susceptibilities and serotypes of Streptococcus pneumoniae: results from the Tigecycline In Vitro Surveillance in Taiwan (TIST) study, 2006-2010. Int J Antimicrob Agents 2013 42:312-316.

16. Liao WH, Lin SH, Lai CC, Tan CK, Liao CH, Huang YT, Wang CY, Hsueh PR: Impact of pneumococcal vaccine on invasive pneumococcal disease in Taiwan. Eur J Clin Microbiol Infect Dis 2010, 29:489-492.

17. Hausdroff WP, Byrand J, Kloek C, Paradiso PR, Siber GR: The contribution of specific pneumococcal serogroups to different disease manifestations: implication for conjugate vaccine formulation and use, part II. Clin Infect Dis 2000, 30:122-140.

18. Scott JA, Hall AJ, Dagan R, Dixon JM, Eykyn SJ, Fenoll A, Hortal M, Jetté LP, Jorgensen JH, Lamothe F, Latorre C, Macfarlane JT, Shlaes DM, Smart LE, Taunay A: Serogroup-specific epidemiology of Streptococcus pneumoniae: associations with age, sex and geography in 7000 episodes of invasive disease. Clin Infect Dis 1996, 22:973-981.

19. Sniadack DH, Schwartz B, Lipman H, et al: Potential interventions for the prevention of childhood pneumonia: geographic and temporal differences in serotype and serogroup distribution of sterile site pneumococcal isolates from children-implications for vaccine strategies. Pediatr Infect Dis J 1995, 14:503-510.

20. Austrian R: The enduring pneumococcus: unfinished business and opportunities for the future. Microb Drug Resist 1997, 3:111-115.

21. Bewick T, Sheppard C, Greenwood S, Slack M, Trotter C, George R, Lim WS: Serotypes associated with the development of pneumococcal para-pneumonic effusion in adults. Eur Respir J 2013, 42:733-741.
22. Liu C, Xiong X, Xu W, Sun J, Wang L, Li J: Serotypes and patterns of anitbiotic resistance in strains causing invasive pneumococcal disease in children less than 5 years of age. PLoS One 2013, 8:e54254.

23. Reijtman V, Fossati S, Hernández C, Sommerfleck P, Bernáldez P, Litterio M, Berberian G, Regueira M, Lopardo H: Serotype distribution of pneumococci isolated from pediatric patients with acute otitis media and invasive infection, and potential coverage of pneumococcal conjugated vaccines. Rev Argent Microbiol 2013, 45:27-33.

doi:10.1186/1471-2334-14-76

Cite this article as: Lai et al:: Decline in the incidence of invasive pneumococcal disease at a medical center in Taiwan, 2000-2012. BMC Infectious Diseases 2014 14:76.

\section{Submit your next manuscript to BioMed Central and take full advantage of:}

- Convenient online submission

- Thorough peer review

- No space constraints or color figure charges

- Immediate publication on acceptance

- Inclusion in PubMed, CAS, Scopus and Google Scholar

- Research which is freely available for redistribution

Submit your manuscript at www.biomedcentral.com/submit
C Biomed Central 